Research Article

\title{
Research on Internal and External Split Ratio of Double-Sided Rotor Permanent Magnet Motor Based on Copper Consumption Density and Current Density
}

\author{
Kai Liu $\mathbb{D}$, Bingyi Zhang, and Guihong Feng \\ School of Electrical Engineering, Shenyang University of Technology, Shenyang 110870, China \\ Correspondence should be addressed to Kai Liu; nbliukai@invt.com.cn
}

Received 2 July 2021; Revised 9 August 2021; Accepted 16 August 2021; Published 27 August 2021

Academic Editor: Sang-Bing Tsai

Copyright ( $\odot 2021$ Kai Liu et al. This is an open access article distributed under the Creative Commons Attribution License, which permits unrestricted use, distribution, and reproduction in any medium, provided the original work is properly cited.

\begin{abstract}
In the traditional split ratio optimization of double-sided rotor permanent magnet motors (DSRPMM), the typical thermal constraint condition is that the total copper consumption of the motor is fixed. This method can only constrain the overall temperature rise of the motor to a certain extent, but it is limited to restrain the local short-time heating of the winding. On the basis of the heat dissipation mode and external size of the motor, an optimal design method of the split ratio based on copper consumption density and current density is presented in this paper. The method restricts the whole heating of the motor and the local short-time heating of the winding by limiting the copper consumption density and current density. The thermal is used as the electromagnetic torque boundary. By analyzing the relationship between the electromagnetic torque and the split ratio, the expression of the optimal split ratio based on the maximum electromagnetic torque is derived. The analysis model is established by using the finite element tool, and the accuracy of the expression is proved. Based on the analysis results, a DSRPMM prototype is made and the experimental test is carried out. The experimental results of the prototype demonstrate the accuracy of the optimal design method of the split ratio based on copper consumption density and current density. The research of this paper provides a theoretical basis for improving the accuracy and reliability of the DSRPMM design.
\end{abstract}

\section{Introduction}

Permanent magnet motors (PMM) not only pursue high efficiency and wide speed range but also have strict requirements on torque density and power density $[1,2]$. On the basis of the traditional single stator and single rotor $\mathrm{PMM}$, in order to further improve the torque density and power density, scholars pay more and more attention to the multiple stator and multiple rotor composite motors. DSRPMM has an internal and external air gap, and the torque and power density of the motor are higher [3]. It is suitable for applications where the installation space of the power system is limited, and the performance index of the driving motor is demanding. The structure of the doublesided rotor will inevitably bring some new theoretical problems to the design and performance analysis. The restrictive relationship between the structural parameters and the electromagnetic performance parameters of the motor is more complex, so the design method of DSRPMM needs to be deeply studied and analyzed.

Scholars have conducted extensive and in-depth research on the structure and design method of this kind of composite motor. In [4], the design method for rational power allocation of internal and external windings of a double-stator PMM used for power distribution of hybrid electric vehicles is established, and the dimension equation and dimension parameter of the motor are analyzed. In [5], the power equation of double-stator PMM is deduced, and the power output characteristics of the motor under different magnetic loads are analyzed. In [6], the influence of internal and external diameters of double-stator PMM on torque density is analyzed, and the maximum torque density is obtained. In [7], the output power equation of the PMM with surface stick structure is deduced, and it provides a 
basis for the selection of parameters in motor design. In $[8,9]$, the analytical expressions of cogging torque for the internal and external stators are derived, and the relation between the relative position of the phase axis of the internal-external winding and the design parameters of the motor is analyzed. In [10], the inductance characteristics of the double-stator permanent magnet brushless motor are analyzed, and the numerical method for calculating unsaturated and saturated inductance of the motor is established. In [11], the fractional slot single pitch winding is used in double-stator PMM for the first time, and the weakening ability of different winding combinations to harmonic potential is analyzed. In $[12,13]$, a novel double stator mixed excitation wind turbine is proposed. For the same volume, the output power and output voltage of the new generator are improved obviously. In $[14,15]$, a multiphase/singlephase rotating cage induction motor with double windings placed in parallel is proposed, and the motor speed regulation and starting characteristics are improved. In $[16,17]$, the design and electromagnetic analysis of the double-stator permanent magnet brushless motor for the electric motorcycle are carried out. The rotor of the motor does not adopt the table-stick structure, but the permanent magnet is embedded in the cup rotor. In [18], weaken the cogging torque of the double-stator hybrid direct drive motor with the series magnetic circuit structure is proposed, and the internal and external stators of the motor are similar to those of a common hybrid variable reluctance motor.

In summary, the method of motor design mostly adopts the traditional split ratio analysis. The typical thermal constraint condition in the traditional split ratio research method is that the total copper consumption of the motor is fixed. This method can only restrain the whole temperature rise of the motor to a certain extent, but it has limited ability to restrain the local short-time heating of the winding. Under different magnetic loads of the motor, the optimal split ratio of the maximum output torque of the motor is changed. The change law of the optimal split ratio of the motor under different magnetic loads needs to be studied in depth. In this paper, on the basis of DSRPMM heat dissipation mode, insulation grade, and external size, an optimal design method of the stator split ratio based on copper consumption density and current density is proposed. The method restricts the overall heating of the motor and the local short-time heating of the winding by limiting the copper consumption density and current density. By analyzing the relationship between the electromagnetic torque and the stator split ratio, the expression of the optimal stator split ratio based on the maximum electromagnetic torque of copper consumption density and current density is derived. The analysis model was established with the finite element tool to verify the optimal stator split ratio. The simulation results verified the accuracy of the analytical calculation results. The internal law between the maximum output torque and the optimal split ratio of the motor under different magnetic loads is studied and analyzed. According to the design method proposed in this paper, a prototype is manufactured and tested. The test results of the prototype are consistent with the analytical calculation results and the finite element simulation results. The accuracy of the design method for DSRPMM proposed in this paper is verified, and it has certain theoretical value and engineering significance.

\section{Extension Structure of DSRPMM}

DSRPMM adopts the structure of concentric internal-external stator, and rotor nesting is shown in Figure 1. The concentric structure can make full use of the radial space inside the motor. Under the condition of not increasing the volume of the motor, the air gap of the motor is changed from one layer to two layers, and the output torque of the motor is improved. On the basis of the traditional single stator and rotor structure, a set of internal stator core and winding are built in. The utilization rate of the vertical space of the motor is improved. The air gap of the motor is changed from one layer to two layers, and the torque output capacity of the motor is improved. DSRPMM adopts the parallel magnetic circuit structure to solve the problem of cross coupling of magnetic fields of double stators of the DSRPMM. The double-surface rotor adopts a magnetic steel structure with built-in multilayer rotors. Compared with the traditional structure, the composite rotor structure can further improve the salient pole ratio and the ratio of reluctance torque of the DSRPMM, and the material utilization rate can be effectively improved. The connection mode of internal and external winding of the $1 / 2$ model is shown in Figure 2. DSRPMM adopts the parallel magnetic circuit structure, and the direction of bilateral air gap flux is opposite. The internal and external windings are connected in the reverse series circuit structure. There are many dimensional parameters to be determined, and the stator split ratio is one of the important parameters of the motor. The stator split ratio of a traditional single stator motor specifies the ratio of the internal diameter to the external diameter, which is essentially the ratio of the structural parameters of the motor.

There are many dimensional parameters to be determined, and the stator split ratio is one of the important parameters of the motor. The stator split ratio of a traditional single stator motor specifies the ratio of the internal diameter to the external diameter, which is essentially the ratio of the structural parameters of the motor. The concept of DSRPMM stator split ratio is different from that of the traditional motor.Two definitions are made as follows: the external splitting ratio, the ratio of the internal diameter of the external stator to the external diameter of the external stator; the internal split ratio, the ratio of the external diameter of the internal stator to the external diameter of the external stator. The main performance parameters of prototype DSRPMM are shown in Table 1, and the analysis model of DSRPMM stator punching is shown in Figure 3. For the convenience of analysis, the following assumptions are made: the no-load permanent magnet flux waveform, the back potential waveform, and the armature current waveform are sinusoidal distribution; the leakage inductance and resistance of internal and external windings of the motor are ignored; the permeability of the permanent magnet is a constant, and it is similar to the permeability of air; the slots are equivalent to parallel teeth, and the external diameter of the stator is fixed and unchanged. 

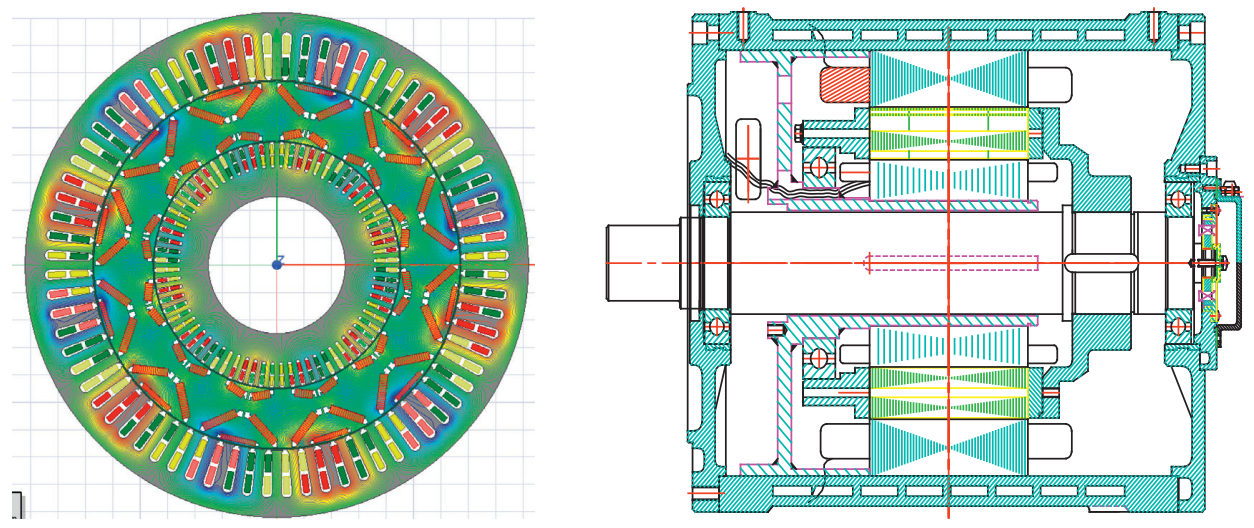

FIgURE 1: Structure diagram of DSRPMM.

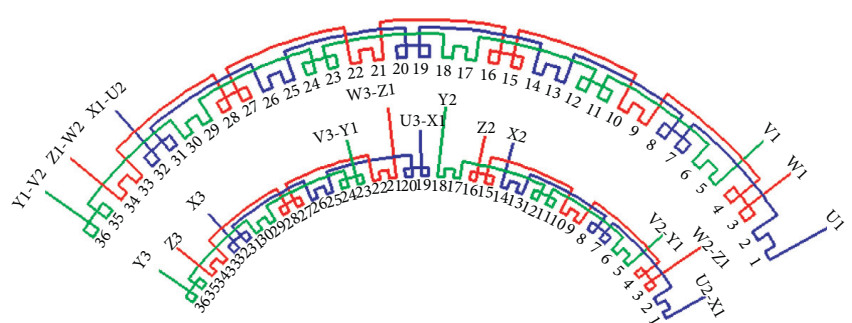

Figure 2: Connection mode of internal and external windings of the $1 / 2$ model.

TABLE 1: Main performance parameters of prototype DSRPMM.

\begin{tabular}{lccc}
\hline Parameters & Value & Parameter & Value \\
\hline Rated power $(\mathrm{kW})$ & 85 & Peak power $(\mathrm{kW})$ & 160 \\
Rated speed $(\mathrm{r} / \mathrm{min})$ & 1200 & Peak speed $(\mathrm{r} / \mathrm{min})$ & 2500 \\
Rated frequency $(\mathrm{Hz})$ & 120 & Peak frequency $(\mathrm{Hz})$ & 250 \\
Rated torque $(\mathrm{N} \mathrm{m})$ & 796 & Peak torque $(\mathrm{N} \mathrm{m})$ & 2000 \\
Rated voltage $(\mathrm{AC})$ & 380 & Battery voltage $(\mathrm{VDC})$ & $520-560$ \\
Protection grade & IP67 & Insulation grade & $H$ \\
Cooling medium & Liquid & Cooling conditions $\left({ }^{\circ} \mathrm{C}\right)$ & 20 \\
\hline
\end{tabular}

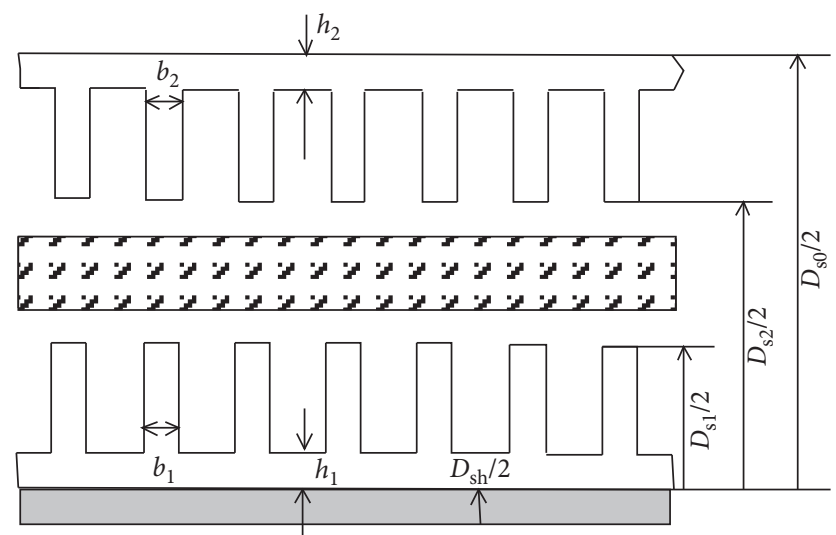

FIgURE 3: The simplified analysis mode of DSRPMM.

\section{Analysis of Split Ratio and Torque Density of DSRPMM}

3.1. Analysis of Electromagnetic Torque and Copper Consumption Density. According to previous studies by scholars, the stator split ratio has no significant effect on iron loss within the range of the common stator split ratio from 0.3 to 0.7 . Therefore, the overall temperature rise of the motor can be constrained by limiting the copper consumption density. While the current density reflects the copper consumption of a single conductor, limiting the current density can constrain the local short-term heating of the winding. The copper consumption density and current density of DSRPMM can be expressed as

$$
\left\{\begin{array}{l}
q_{\mathrm{cu}}=\frac{4 p_{\mathrm{Cu}}}{\pi D_{0} l_{\mathrm{ef}}}, \\
J=\frac{I_{a}}{A_{\mathrm{cond}}},
\end{array}\right.
$$

where $D_{0}$ is the external diameter of the stator core, and its value is fixed, $p_{\mathrm{cu}}$ is the copper consumption of the motor, $l_{\mathrm{ef}}$ is the effective core length of the motor, $I_{a}$ is the armature current, and $A_{\text {cond }}$ is the cross-sectional area of a single conductor. The electromagnetic force received by the singleturn coil in the internal and external stator cores of DSRPMM can be expressed as

$$
\left\{\begin{array}{l}
F_{\text {cond } 1}=2 B_{\delta 1} I_{a 1} l_{\mathrm{ef}}, \\
F_{\text {cond } 2}=2 B_{\delta 2} I_{a 2} l_{\mathrm{ef}},
\end{array}\right.
$$

where $B_{\delta 1}$ and $B_{\delta 2}$ are internal and external air gap flux densities, respectively, and $I_{a 1}$ and $I_{a 2}$ are the current flowing in the internal and external armature windings, respectively. It can be deduced that the current of DSRPMM acts with the internal and external air gap magnetic field, respectively, to generate the electromagnetic torque, and copper consumption can be expressed as 


$$
\begin{aligned}
& \left\{\begin{array}{l}
T_{\mathrm{em} 1}=\frac{3 \sqrt{2}}{2} B_{\delta 1} I_{a 1} l_{\mathrm{ef}} D_{s 1} N_{1}, \\
T_{\mathrm{em} 2}=\frac{3 \sqrt{2}}{2} B_{\delta 2} I_{a 2} l_{\mathrm{ef}} D_{s 2} N_{2}, \\
p_{\mathrm{Cu} 2}=3 I_{a 2}^{2} r_{a}=3 I_{a 2}^{2} \rho_{\mathrm{Cu}} \frac{2 N_{2} l_{\mathrm{ef}}}{A_{\mathrm{cond} 2}} \\
p_{\mathrm{Cu} 1}=3 I_{a 1}^{2} r_{a}=3 I_{a 1}^{2} \rho_{\mathrm{Cu}} \frac{2 N_{1} l_{\mathrm{ef}}}{A_{\mathrm{cond} 1}} \\
A_{\mathrm{cond} 1}=\frac{A_{s 1} S_{f 1} Z_{1}}{6 N_{1}}, \\
A_{\mathrm{cond} 2}=\frac{A_{s 2} S_{f 2} Z_{2}}{6 N_{2}},
\end{array}\right.
\end{aligned}
$$

where $D_{S 1}$ and $D_{S 2}$ are the external diameter of the internal stator core and the internal diameter of the external stator core, respectively, $N_{1}$ and $N_{2}$ are the number of series turns per phase of the internal and external windings, respectively, $A_{\text {cond1 }}$ and $A_{\text {cond2 }}$ are the cross-sectional areas of the singleturn coil of the internal and external windings, respectively, $A_{s 1}$ and $A_{s 2}$ are the areas of internal and external slots, respectively, $S_{f 1}$ and $S_{f 2}$ are the full rate of internal and external slots, respectively, and $Z_{1}$ and $Z_{2}$ are the number of internal and external slots, respectively; it can be deduced that when the copper consumption density is limited, the electromagnetic torque of DSRPMM can be expressed as

$$
\begin{aligned}
& T_{\mathrm{em} 1}=\frac{3 \sqrt{2}}{2} \frac{D_{s 1}}{D_{0}} l_{\mathrm{ef}} \frac{B_{\delta 1}}{B_{\max 1}} D_{0} B_{\max 1} N_{1} \sqrt{\frac{q_{\mathrm{Cu} 1} \pi D_{0} A_{s 1} S_{f 1} Z_{1}}{36 N_{1} \rho_{\mathrm{Cu}}}} \\
& =\frac{3 \sqrt{2}}{2} \lambda_{1} D_{0}^{(3 / 2)} l_{\mathrm{ef}} \beta_{1} B_{\max 1} \sqrt{\frac{q_{\mathrm{Cu} 1} \pi A_{s 1} S_{f 1} Z_{1}}{36 \rho_{\mathrm{Cu}}}}, \\
& T_{\mathrm{em} 2}=\frac{3 \sqrt{2}}{2} \frac{D_{s 2}}{D_{0}} l_{\mathrm{ef}} \frac{B_{\delta 2}}{B_{\max 2}} D_{0} B_{\max 2} N_{2} \sqrt{\frac{q_{\mathrm{Cu} 2} \pi D_{0} A_{s 2} S_{f 2} Z_{2}}{36 N_{2} \rho_{\mathrm{Cu}}}} \\
& =\frac{3 \sqrt{2}}{2} \lambda_{2} D_{0}^{(3 / 2)} l_{\mathrm{ef}} \beta_{2} B_{\max 2} \sqrt{\frac{q_{\mathrm{Cu} 2} \pi A_{s 2} S_{f 2} Z_{2}}{36 \rho_{\mathrm{Cu}}}}, \\
& \left\{\begin{array}{l}
\lambda_{1}=\frac{D_{s 1}}{D_{0}}, \\
\lambda_{2}=\frac{D_{s 2}}{D_{0}}, \\
\beta_{1}=\frac{B_{\delta 1}}{B_{\max 1}} \\
\beta_{2}=\frac{B_{\delta 2}}{B_{\max 2}},
\end{array}\right.
\end{aligned}
$$

where $\lambda_{1}$ and $\lambda_{2}$ are the internal and external split ratios of DSRPMM, respectively, $\beta_{1}$ and $\beta_{2}$ are the internal and external stator flux density coefficients, respectively, and $B_{\max 1}$ and $B_{\max 2}$ are the maximum flux densities of the internal and external stators, respectively.
3.2. Analysis of Electromagnetic Torque and Current Density. The current density of DSRPMM reflects the copper consumption density of a single conductor. Limiting the current density can restrain the local short-time heating of the winding. It can be deduced that when the current density is 
limited, the electromagnetic torque of DSRPMM can be expressed as

$$
\left\{\begin{array}{l}
T_{\mathrm{em} 1}^{\prime}=\frac{3 \sqrt{2}}{2} \frac{B_{\delta 1}}{B_{\max 1}} l_{\mathrm{ef}} \frac{D_{s 1}}{D_{0}} B_{\max 1} D_{0} N_{1} \frac{J_{1} A_{s 1} S_{f 1} Z_{1}}{6 N_{1}} \\
=\frac{3 \sqrt{2}}{2} \lambda_{1} D_{0} l_{\mathrm{ef}} \beta_{1} B_{\max 1} \frac{J_{1} A_{s 1} S_{f 1} Z_{1}}{6}, \\
T_{\mathrm{em} 2}^{\prime}=\frac{3 \sqrt{2}}{2} \frac{B_{\delta 2}}{B_{\max 2}} l_{\mathrm{ef}} \frac{D_{s 2}}{D_{0}} B_{\max 2} D_{0} N_{2} \frac{J_{1} A_{s 1} S_{f 1} Z_{1}}{6 N_{2}} \\
=\frac{3 \sqrt{2}}{2} \lambda_{2} D_{0} l_{\mathrm{ef}} \beta_{2} B_{\max 2} \frac{J_{2} A_{s 2} S_{f 2} Z_{2}}{6} .
\end{array}\right.
$$

Since the external diameter of the DSRPMM external stator is fixed, the volume of the motor is also fixed.Therefore, the analysis of DSRPMM torque density based on copper consumption density and current density can be equivalent to the analysis of motor electromagnetic torque.

\section{Analytical Analysis of Optimal Split Ratio of DSRPMM}

4.1. Analysis of the Area of Internal and External Slots. In the above derivation, the slot areas of the internal and external stators of DSRPMM are variables, which need to be further calculated. On the one hand, the groove area of the internal and external stator is closely related to the split ratio of the internal and external stator, so it is necessary to analyze the relationship between the groove area and the split ratio. On the other hand, the distribution of magnetic field lines in the motor is different due to the coordination of different pole slots. Ignoring the magnetic leakage effect of the motor, the motor stator tooth flux and the air gap magnetic flux are the same in a pole distance. The dimensions of internal and external teeth and yoke of DSRPMM can be expressed as

$$
\left\{\begin{array}{l}
b_{1}=\frac{\beta_{1} \pi D_{s 1}}{Z_{1}}, \\
b_{2}=\frac{\beta_{2} \pi D_{s 2}}{Z_{2}}, \\
h_{1}=\frac{1}{2} \frac{\beta_{1} \pi D_{s 1}}{Z_{1}}, \\
h_{2}=\frac{1}{2} \frac{\beta_{2} \pi D_{s 2}}{Z_{2}} .
\end{array}\right.
$$

On the basis of the simplified motor analysis model given above, the areas of the internal and external slots of DSRPMM can be expressed as

$$
\left\{\begin{array}{l}
A_{s 1}=\frac{\pi D_{s 1}^{2}}{4 Z_{1}}\left[1-\left(\frac{D_{s h}+2 h_{1}}{D_{s 1}}\right)\right]-b_{1}\left(\frac{D_{s 1}-D_{s h}}{2}-h_{1}\right) \\
=\frac{\pi D_{s h}^{2}}{4 Z_{1}}\left\{\left(\frac{D_{s 1}}{D_{s h}}\right)^{2}\left[1-\frac{\pi}{n p}\left(\frac{\pi}{n p}-2\right)\left(\frac{B_{\delta 1}}{B_{\max 1}}\right)^{2}-\frac{2 B_{\delta 1}}{B_{\max 1}}\right]\right. \\
+\frac{\pi D_{s h}^{2}}{4 Z_{1}}\left\{-2\left(\frac{D_{s 1}}{D_{s h}}\right)\left(\frac{\pi}{n p}-1\right) \frac{B_{\delta 1}}{B_{\max 1}}-1\right\}, \\
A_{s 2}=\frac{\pi D_{s 0}^{2}}{4 Z_{2}}\left[\left(1-\frac{2 h_{2}}{D_{s 0}}\right)^{2}-\left(\frac{D_{s 2}}{D_{s 0}}\right)^{2}\right]-b_{2}\left(\frac{D_{s 0}-D_{s 2}}{2}-h_{2}\right) \\
=\frac{\pi D_{s 0}^{2}}{4 Z_{2}}\left\{\left(\frac{D_{s 2}}{D_{s 0}}\right)^{2}\left[\frac{\pi}{n p}\left(\frac{\pi}{n p}+2\right)\left(\frac{B_{\delta 1}}{B_{\max 1}}\right)^{2}+\frac{2 B_{\delta 1}}{B_{\max 1}}-1\right]\right\} \\
\frac{\pi D_{s 0}^{2}}{4 Z_{2}}\left\{-2\left(\frac{D_{s 2}}{D_{s 0}}\right)^{2}\left(\frac{\pi}{n p}+1\right) \frac{B_{\delta 1}}{B_{\max 1}}+1\right\} .
\end{array}\right.
$$


In the process of DSRPMM, the ratio between the external diameter $D_{s 0}$ of the external stator and the internal diameter $D_{s h}$ of the internal stator should also be considered, and $D_{s h}=k D_{s 0}$ and $n=Z / p$ are defined. On the one hand, the ratio of $D_{s 1} / D_{s 0}$ is smaller than the ratio of $D_{s 2} / D_{s 0}$. On the other hand, the ratio of $D_{s 1} / D_{s 0}$ is greater than the ratio of
$D_{s h} / D_{S 0}$. Only when the above two conditions are met at the same time, it is meaningful to analyze the influence of DSRPMM internal and external split ratio on the motor torque. It can be deduced that the area of the internal slot of DSRPMM can be expressed as

$$
\left\{\begin{array}{l}
A_{s 1}=\frac{\pi D_{s 0}^{2}}{4 Z_{1}}\left\{\left(\frac{D_{s 1}}{D_{s 0}}\right)^{2}\left[1-\frac{\pi}{n p}\left(\frac{\pi}{n p}-2\right)\left(\frac{B_{\delta 1}}{B_{\max 1}}\right)^{2}-\frac{2 B_{\delta 1}}{B_{\max 1}}\right]\right\} \\
=\frac{\pi D_{s 0}^{2}}{4 Z_{1}}\left\{-2\left(\frac{D_{s 1}}{D_{s 0}}\right) k\left(\frac{\pi}{n p}-1\right) \frac{B_{\delta 1}}{B_{\max 1}}-k^{2}\right\}, \\
=\frac{\pi D_{s 0}^{2}}{4 Z_{1}}\left(A_{1} \lambda_{1}^{2}-2 B_{1} \lambda_{1}-k^{2}\right), \\
A_{2}=\left(\frac{\pi}{k p}+1\right) \beta_{2} . \\
=\frac{\pi D_{s 0}^{2}}{4 Z_{2}}\left\{-\left(\frac{D_{s 2}}{D_{s 0}}\right)\left(\frac{\pi}{k p}+1\right) \frac{\pi}{A_{\delta 1}}+1\right\} \\
\left.B_{1}=\frac{\pi}{n p}\left(\frac{\pi}{n p}-2\right) \beta_{1}^{2}-2 \beta_{1}\right] \\
A_{s 2}=\frac{\pi D_{s 0}^{2}}{4 Z_{2}}\left\{\left(\frac{D_{s 2}}{D_{s 0}}\right)^{2}\left[\frac{\pi}{k p}\left(\frac{\pi}{k p}+2\right)\left(\frac{B_{\delta 1}}{B_{\max 1}}\right)^{2}+2 \frac{B_{\delta 1}}{B_{\max 1}}-1\right]\right.
\end{array}\right\}
$$


4.2. Optimal Splitting Ratio Analysis for Limiting Copper Consumption Density. On the basis of limiting the copper consumption density, the relationship between the electromagnetic torque of DSRPMM with the internal and external split ratio can be expressed as follows:

$$
\left\{\begin{array}{l}
T_{\mathrm{em} 1}=\frac{3 \sqrt{2}}{2} \lambda_{1} D_{0}^{(3 / 2)} l_{\mathrm{ef}} \beta_{1} B_{\max 1} \sqrt{\frac{q_{\mathrm{Cu} 1} \pi A_{s 1} S_{f 1} Z_{1}}{36 \rho_{\mathrm{Cu}}}} \\
=\frac{3 \sqrt{2}}{2} \lambda_{1} \pi D_{0}^{(5 / 2)} l_{\mathrm{ef}} \beta_{1} B_{\max 1} \sqrt{\frac{q_{\mathrm{Cu} 1} S_{f 1}\left(A_{1} \lambda_{1}^{2}-2 B_{1} \lambda_{1}-k^{2}\right)}{144 \rho_{\mathrm{Cu}}}} \\
T_{\mathrm{em} 2}=\frac{3 \sqrt{2}}{2} \lambda_{2} D_{0}^{(3 / 2)} l_{\mathrm{ef}} \beta_{2} B_{\max 2} \sqrt{\frac{q_{\mathrm{Cu} 2} \pi A_{s 2} S_{f 2} Z_{2}}{36 \rho_{\mathrm{Cu}}}} \\
=\frac{3 \sqrt{2}}{2} \lambda_{2} \pi D_{0}^{(5 / 2)} l_{\mathrm{ef}} \beta_{2} B_{\mathrm{max} 2} \sqrt{\frac{q_{\mathrm{Cu} 2} S_{f 2}\left(A_{2} \lambda_{2}^{2}-2 B_{2} \lambda_{2}+1\right)}{144 \rho_{\mathrm{Cu}}}} \\
T_{\mathrm{em} 12}=T_{\mathrm{em} 1}+T_{\mathrm{em} 2} \\
=\frac{3 \sqrt{2}}{2} \pi D_{0}^{(5 / 2)} l_{\mathrm{ef}} \sqrt{\frac{S_{f}}{144 \rho_{\mathrm{Cu}}}} \bullet
\end{array}\right.
$$

$T_{\mathrm{em} 12}$ is the electromagnetic torque of DSRPMM with limited copper consumption density. It can be obtained from the equation that when $\beta$ and $q_{\mathrm{Cu}}$ are constant, the solution of the maximum electromagnetic torque of DSRPMM is actually the extreme of a multivariate function $f_{\text {em12 }}\left(\lambda_{1}, \lambda_{2}\right)=\lambda_{1} \sqrt{A_{s 1}}+\lambda_{2} \sqrt{A_{s 2}}$. The optimal internal and external split ratio can be expressed as

$$
\left\{\begin{array}{l}
\lambda_{\mathrm{op} 1}=\frac{\sqrt{3 B_{1}+\left(9 B_{1}^{2}+8 A_{1} k^{2}\right)}}{4 A_{1}}, \\
\lambda_{\mathrm{op} 2}=\frac{3 B_{2}-\sqrt{9 B_{2}^{2}-8 A_{2}}}{4 A_{2}} .
\end{array}\right.
$$

The relationship between the internal split ratio with $p$ and $\beta$ of DSRPMM is shown in Figure 4 , and the relationship between the external split ratio with $p$ and $\beta$ of DSRPMM is shown in Figure 5.
It can be seen from the figure that when the copper density is limited, the optimal internal and external split ratio of DSRPMM is different from the flux density coefficient and pole number. When the flux density coefficient is constant, the optimal internal split ratio decreases with the increase of the number of poles, and the optimal external split ratio increases with the increase of the number of poles. When the number of poles is constant, the change law of the internal and external split ratio with the flux density coefficient is the same. The optimal internal and external split ratio of DSRPMM decreases with the increase of the magnetic flux density coefficient. The limitation parameters of the prototype are as follows: $q_{\mathrm{Cu} 1}=13 \mathrm{~kW} / \mathrm{m}^{2}, \quad q_{\mathrm{Cu} 2}=56 \mathrm{~kW} / \mathrm{m}^{2}, \quad p_{1}=p_{2}=6$, and $B_{\max 1}=B_{\max 2}=1.7 \mathrm{~T}$. The relationship between electromagnetic torque with internal split ratio and $\beta$ of DSRPMM is shown in Figure 6, and the relationship between electromagnetic torque with external split ratio and $\beta$ of DSRPMM is shown in Figure 7. 


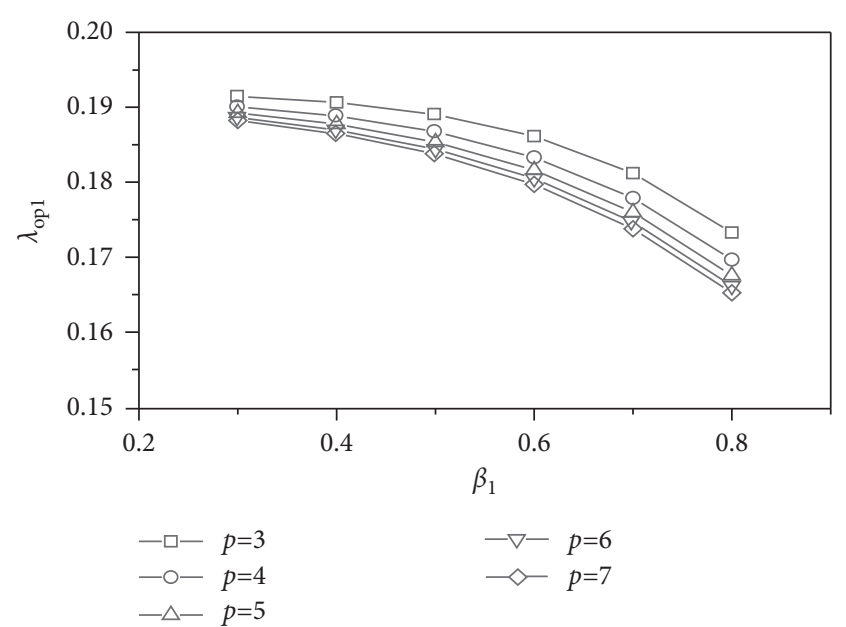

FIGURE 4: Relationship between the internal split ratio with $p$ and $\beta$.

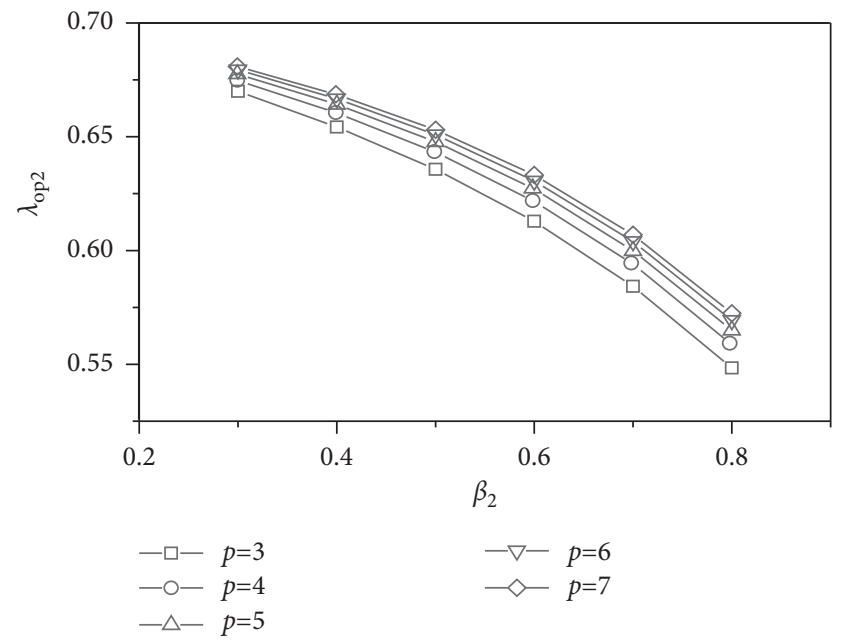

FIGURE 5: Relationship between the external split ratio with $p$ and $\beta$.

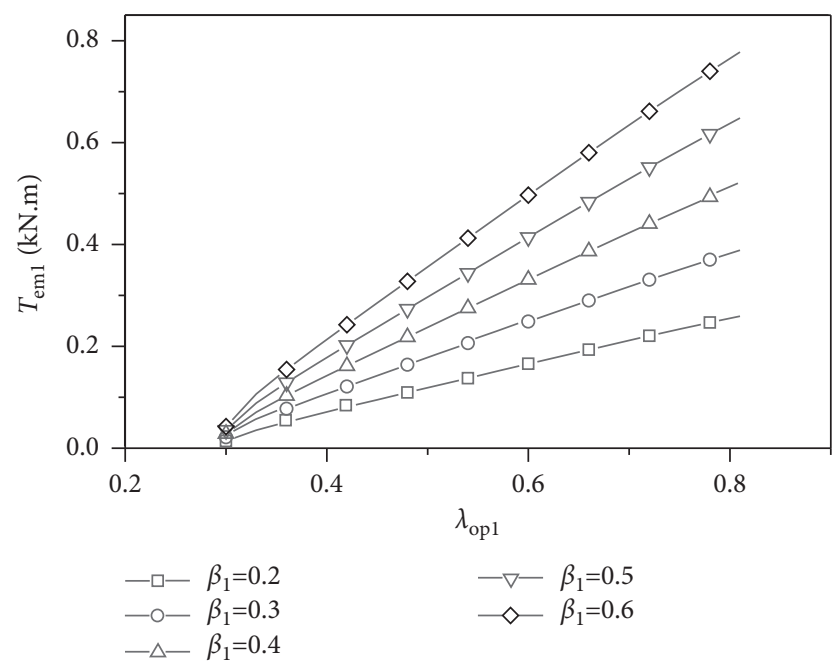

FIGURE 6: Relationship between torque with internal split ratio and $\beta$.
It can be seen from the figure that when the copper density is limited, the variation law of the output electromagnetic torque of DSRPMM is different with the split ratio and the magnetic flux density coefficient. When the flux density coefficient remains constant, the output electromagnetic torque of DSRPMM increases with the increase of the internal split ratio, and the output electromagnetic torque shows a trend of increasing first and then decreasing with the increase of the external split ratio. With the increase of the flux density coefficient of DSRPMM, the output electromagnetic torque increases gradually when the internal and external split ratios remain unchanged. Therefore, when the copper consumption density is limited, there is an optimal external split ratio of DSRPMM. The larger the flux density coefficient, the smaller the optimal external split ratio and the larger the maximum electromagnetic torque.The influence of the external split ratio on electromagnetic torque is greater than the internal split ratio. The external split ratio should be matched first, and then, the internal split ratio should be further matched on the basis of the external split ratio.

4.3. Optimal Splitting Ratio Analysis for Limiting Current Density. On the basis of limiting the current density, the relationship between the electromagnetic torque of DSRPMM with the internal and external split ratio can be expressed as follows:

$$
\begin{aligned}
& T_{\mathrm{em} 1}^{\prime}=\frac{3 \sqrt{2}}{2} \lambda_{1} D_{0} l_{\mathrm{ef}} \beta_{1} B_{\max 1} \frac{J_{1} A_{s 1} S_{f 1} Z_{1}}{6} \\
& =\frac{3 \sqrt{2}}{2} \lambda_{1} \pi D_{0}^{3} l_{\mathrm{ef}} \beta_{1} B_{\max } \frac{J_{1} S_{f}\left(A_{1} \lambda_{1}^{2}-2 B_{1} \lambda_{1}-k^{2}\right)}{24}, \\
& T_{\text {em } 2}^{\prime}=\frac{3 \sqrt{2}}{2} \lambda_{2} D_{0} l_{\mathrm{ef}} \beta_{2} B_{\max 2} \frac{J_{2} A_{s 2} S_{f 2} Z_{2}}{6} \\
& \begin{array}{l}
=\frac{3 \sqrt{2}}{2} \lambda_{2} \pi D_{0}^{3} l_{\mathrm{ef}} \beta_{2} B_{\max 2} \frac{J_{1} S_{f}\left(A_{2} \lambda_{2}^{2}-2 B_{2} \lambda_{2}+1\right)}{24}, \\
T_{\mathrm{em} 12}^{\prime}=T_{\mathrm{em} 1}^{\prime}+T_{\mathrm{em} 2}^{\prime}
\end{array} \\
& =\frac{3 \sqrt{2}}{2} \pi D_{0}^{3} l_{\mathrm{ef}} S_{f} J \bullet \\
& \left(\lambda_{1} \beta_{1} B_{\max 1} \frac{\left(A_{1} \lambda_{1}^{2}-2 B_{1} \lambda_{1}-k^{2}\right)}{24}+\lambda_{2} \beta_{2} B_{\max 2} \frac{\left(A_{2} \lambda_{2}^{2}-2 B_{2} \lambda_{2}+1\right)}{24}\right) \\
& J_{1}=J_{2}=J .
\end{aligned}
$$

$T_{\mathrm{em} 12}$ ' is the electromagnetic torque of DSRPMM with limited current density. It can be obtained from the equation when $\beta$ and $J$ are constant, the solution of the maximum electromagnetic torque of DSRPMM is actually the extreme 


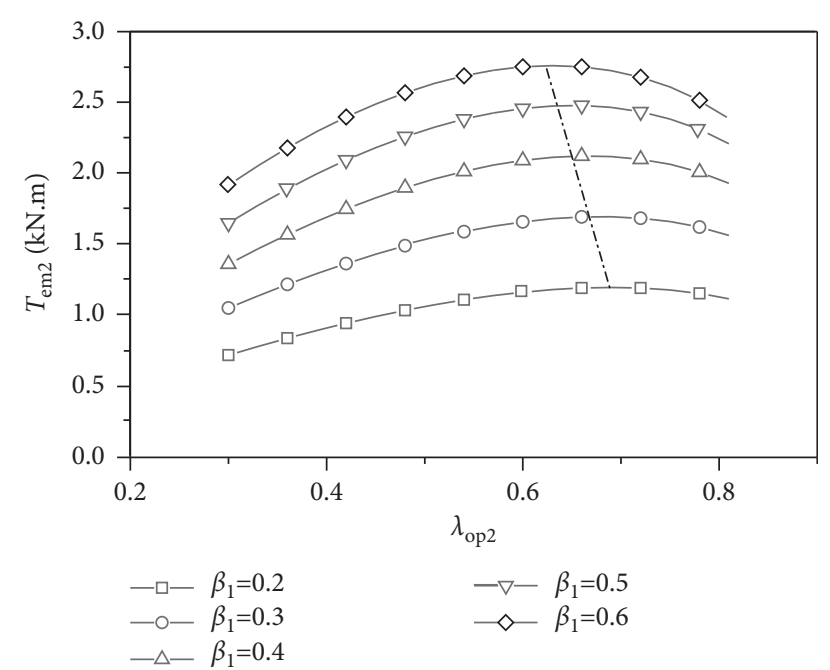

FIGURE 7: Relationship between torque with external split ratio and $\beta$.

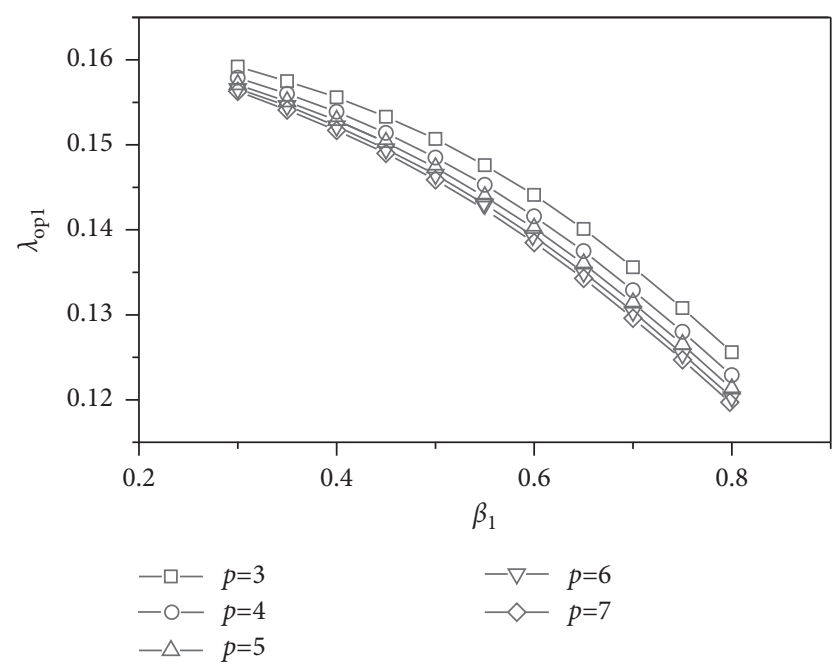

FIGURE 8: Relationship between the internal split ratio with $p$ and $\beta$.

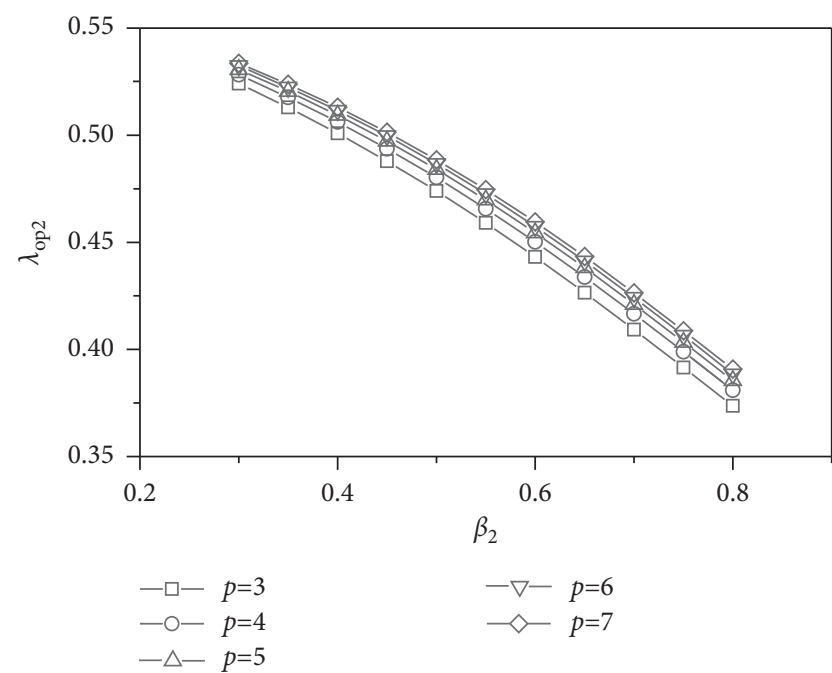

Figure 9: Relationship between the external split ratio with $p$ and $\beta$. of a multivariate function $f_{e m 12}^{\prime}\left(\lambda_{1}, \lambda_{2}\right)=\lambda_{1} A_{s 1}+\lambda_{2} A_{s 2}$. The optimal internal and external split ratio can be expressed as

$$
\left\{\begin{array}{l}
\lambda_{\mathrm{op} 1}=\frac{2\left(B_{1}+\sqrt{B_{1}^{2}+\left(3 A_{1} k^{2}\right) / 4}\right)}{3 A_{1}}, \\
\lambda_{\mathrm{op} 2}=\frac{2\left(B_{2}-\sqrt{B_{2}^{2}-\left(3 A_{2}\right) / 4}\right)}{3 A_{2}} .
\end{array}\right.
$$

The relationship between the internal split ratio with $p$ and $\beta$ of DSRPMM is shown in Figure 8, and the relationship between the external split ratio with $p$ and $\beta$ of DSRPMM is shown in Figure 9.

It can be seen from the figure that when the current density is limited, the optimal internal and external split ratio of DSRPMM is different from the flux density coefficient and pole number. When the flux density coefficient is constant, the optimal internal split ratio decreases with the increase of the number of poles, and the optimal external split ratio increases with the increase of the number of poles. When the number of poles is constant, the change law of the internal and external split ratio with the flux density coefficient is the same. The optimal internal and external split ratio of DSRPMM decreases with the increase of the magnetic flux density coefficient. The limitation parameters of the prototype are as follows: $J_{1}=J_{2}=160 \times 10^{5} \mathrm{~A} / \mathrm{m}^{2}$, $p_{1}=p_{2}=6$, and $B_{\max 1}=B_{\max 2}=1.7 \mathrm{~T}$. The relationship between electromagnetic torque with internal split ratio and $\beta$ of DSRPMM is shown in Figure 10. The relationship between electromagnetic torque with external split ratio and $\beta$ of DSRPMM is shown in Figure 11.

It can be seen from the figure that when the current density is limited, the variation law of the output electromagnetic torque of DSRPMM is different with the split ratio and the magnetic flux density coefficient. When the flux density coefficient remains constant, the output electromagnetic torque of DSRPMM increases with the increase of the internal split ratio, and the output electromagnetic torque shows a trend of increasing first and then decreasing with the increase of the external split ratio. With the increase of the flux density coefficient of DSRPMM, the output electromagnetic torque increases gradually when the internal and external split ratios remain unchanged. Therefore, when the current density is limited, there is an optimal external split ratio of DSRPMM. The larger the flux density coefficient, the smaller the optimal external split ratio and the larger the maximum electromagnetic torque. The influence of the external split ratio on electromagnetic torque is greater than the internal split ratio.

\section{Analysis of Optimal Split Ratio Based on Limited Copper Consumption Density and Current Density}

5.1. Analytical Analysis of Optimal Split Ratio. The current research mainly focuses on the influence of the motor split ratio on power and torque. However, the analysis and 


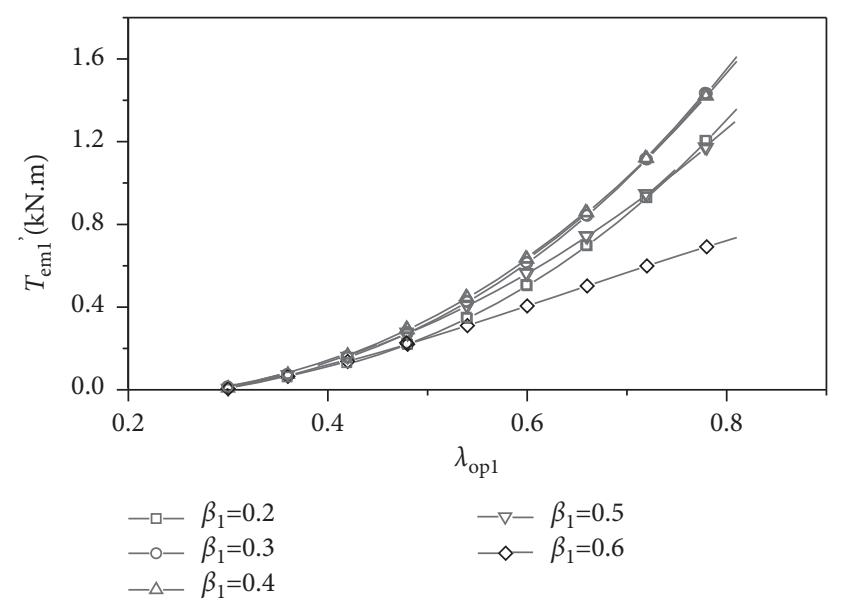

FIGURE 10: Relationship between torque with internal split ratio and $\beta$.

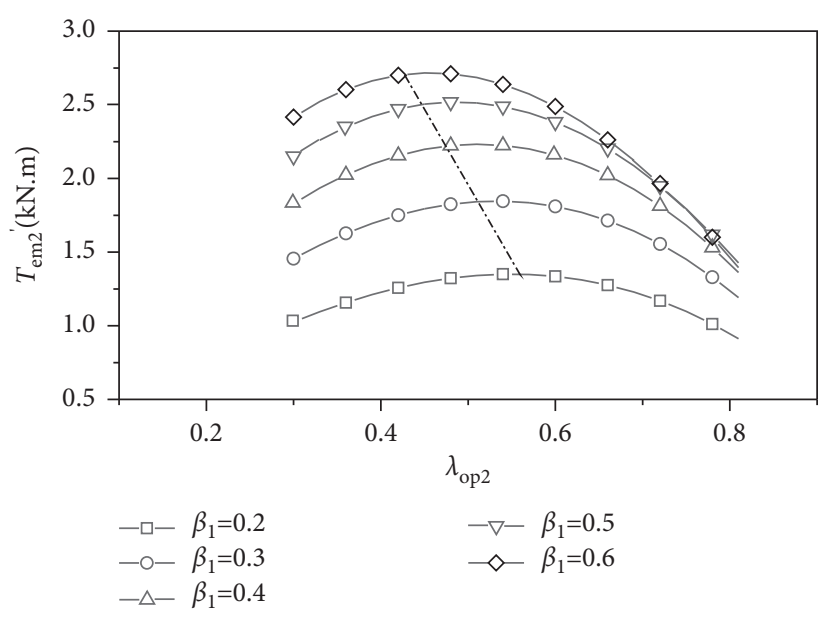

FIGURE 11: Relationship between torque with external split ratio and $\beta$.

research on the output electromagnetic torque of the motor under different magnetic loads are few. Under different magnetic loads, the optimal split ratio of the maximum output torque of DSRPMM varies. Therefore, it is necessary to study the internal law of DSRPMM magnetic load and optimal split ratio. On the basis of the above analysis, the copper consumption density and current density of the motor are limited, $q_{\mathrm{cul}}=13 \mathrm{~kW} / \mathrm{m}^{2}, J_{1}=160 \times 10^{5} \mathrm{~A} / \mathrm{m}^{2}$, $q_{\mathrm{cu} 2}=56 \mathrm{~kW} / \mathrm{m}^{2}$, and $J_{2}=160 \times 10^{5} \mathrm{~A} / \mathrm{m}^{2}$. The relationship between the maximum electromagnetic torque and internal split ratio when the flux density coefficients of DSRPMM at $0.2,0.4$, and 0.6 is shown in Figure 12 .

It can be seen from the figure that when the copper consumption density and current density are limited, the output electromagnetic torque of DSRPMM increases with the increase of the flux density coefficient. The optional region of the internal split ratio increases. The two output electromagnetic torque curves intersect when the flux density coefficient is less than 0.6 . The ratio of internal splits at the intersection point increases with the increase of the flux density coefficient. There is no intersection point of the
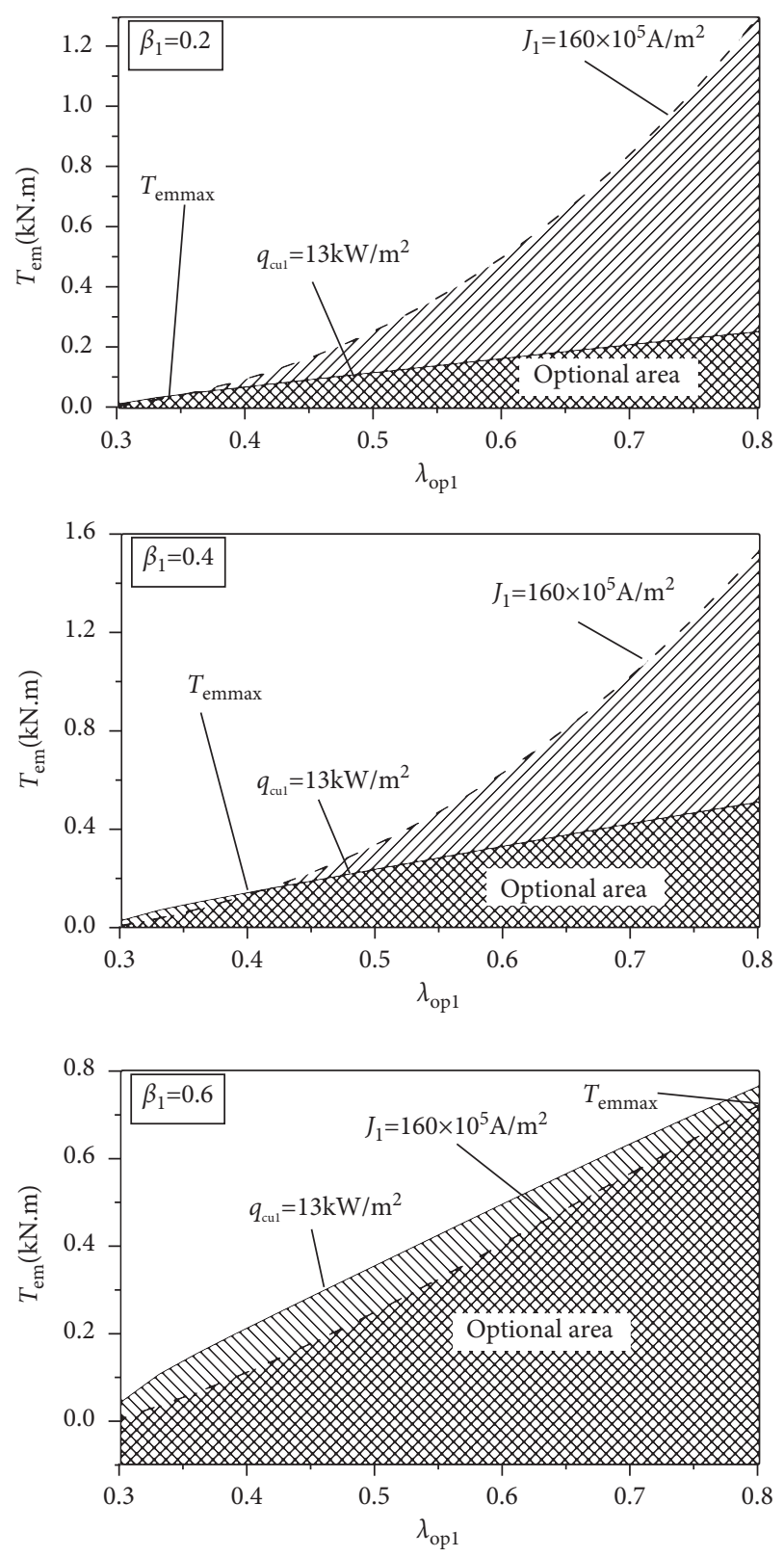

FIgURE 12: Relationship between torque with the internal split ratio.

electromagnetic torque curve under the restriction of copper consumption density and the restriction of current density when the flux density coefficient is greater than or equal to 0.6. The output electromagnetic torque curve of limited copper density surrounds the electromagnetic torque curve of limited current density. The output torque is mainly determined by the current density, which should be paid attention to when the motor is designed. The relationship between the maximum electromagnetic torque and external split ratio when the flux density coefficients of DSRPMM at $0.2,0.4$, and 0.6 is shown in Figure 13 .

It can be seen from the figure that when the copper consumption density and current density are limited, the output electromagnetic torque of DSRPMM increases with 

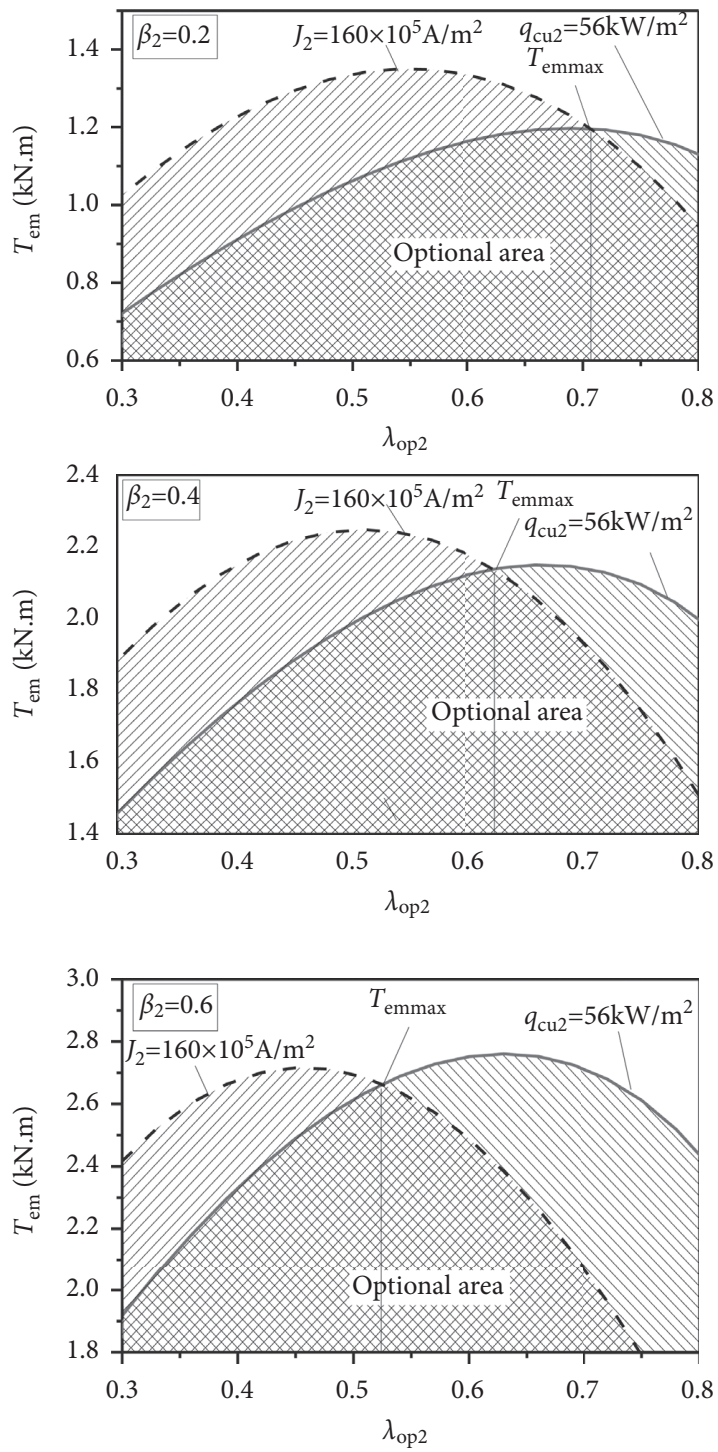

FIGURE 13: Relationship between torque with the external split ratio.

the increase of the flux density coefficient. The optional region of the output electromagnetic torque increases first and then decreases. The optimal split ratio limiting the copper consumption density is larger than the optimal split ratio limiting the current density. There is an intersection point of the output electromagnetic torque curve of DSRPMM with limited copper consumption density and limited current density. The ratio of external splits at the intersection point decreases with the increase of the flux density coefficient.

5.2. Finite Element of Optimal Split Ratio. Based on the analytical analysis of the optimal internal split ratio, the finite element analysis model of the optimal internal split ratio of the stator is established. The finite element simulation and analytical calculation results of the relation curve between electromagnetic torque and internal split ratio of DSRPMM are shown in Figure 14.

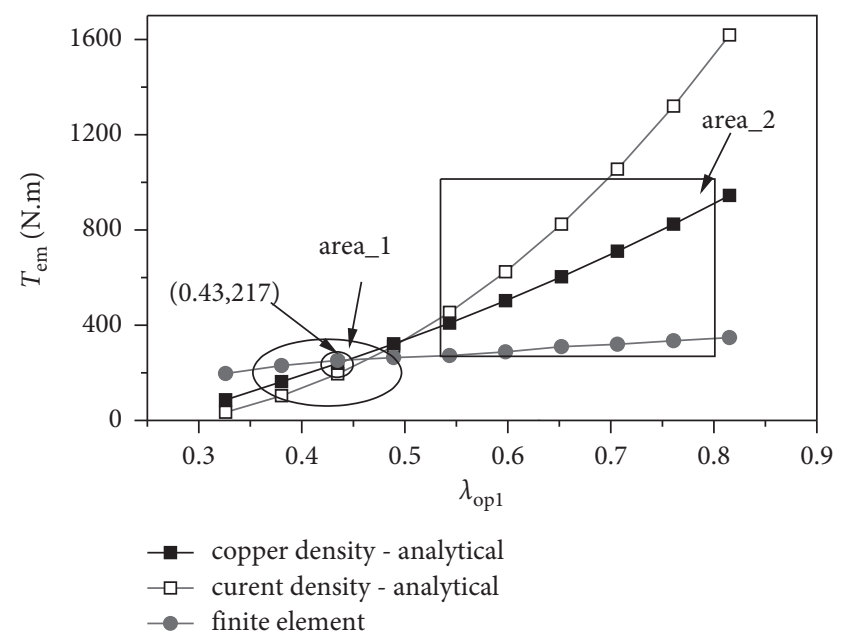

FIGURE 14: Contrast relationship between torque with the internal split ratio.

It can be seen from the figure, when DSRPMM internal split ratio is greater than 0.55 , the finite element simulation torque is less than the analytical value of electromagnetic torque calculated by limiting copper consumption density and torque density. There is a big difference between the analytical calculation with the finite element simulation results. This is mainly because when the value of internal split ratio is too large, and it exceeds the actual optional value of the motor, and the analytic calculation method will be distorted. The calculation result has less reference significance. The analytical value of electromagnetic torque is close to the finite element simulation value when the internal split ratio of DSRPMM is less than 0.55 . The variation law of the calculated values is similar to that of the finite element simulation values, which verifies the accuracy of the theoretical analysis above. Due to the limitations of structural space, the meaningful value range of the internal split ratio is between 0.3 and 0.6 . The analytical analysis of the internal split ratio of DSRPMM in this paper can effectively provide the basis for the design of the motor. The finite element simulation and analytical calculation results of the relation curve between electromagnetic torque and external split ratio of DSRPMM are shown in Figure 15.

It can be seen from the figure, the finite element simulation value of DSRPMM electromagnetic torque is generally smaller than the analytical calculated value, but the change rules of both are similar. The finite element simulation value of electromagnetic torque increases with the increase of the external split ratio when the external split ratio is less than 0.61 . The finite element simulation value of electromagnetic torque decreases with the increase of the external split ratio when the external split ratio is greater than 0.61 . The analytical value of the electromagnetic torque increases with the increase of the external splitting ratio when the external splitting ratio is less than 0.63. The analytical value of the electromagnetic torque decreases with the increase of the external splitting ratio when the external splitting ratio is greater than 0.63 . The finite element simulation value of DSRPMM electromagnetic torque reaches 


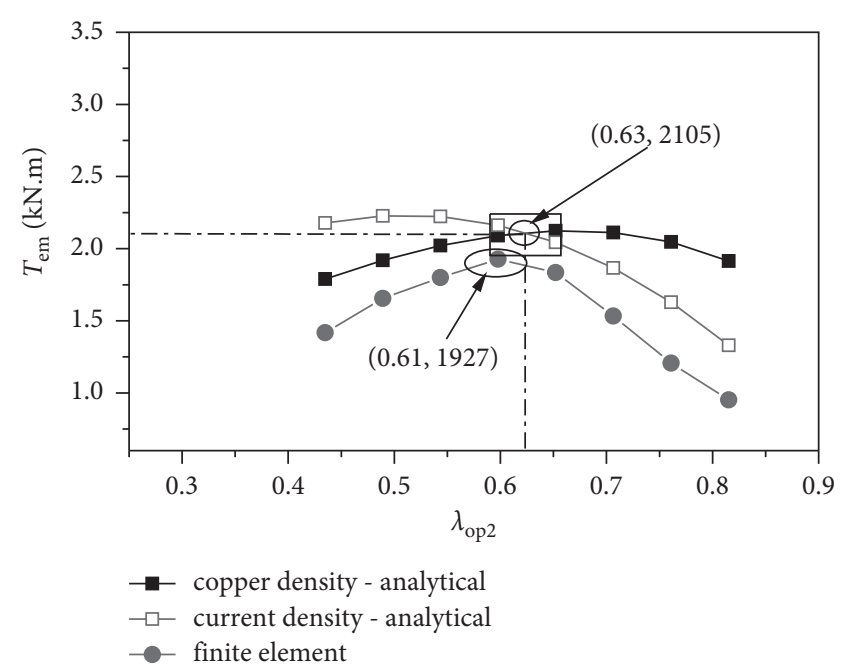

FIGURE 15: Contrast relationship between torque with the external split ratio.

the maximum value when the external split ratio is around 0.61 , and its value is 1927 N.m. The analytical calculation value of the electromagnetic torque limiting the copper consumption density and the torque density reaches the maximum value when the external split ratio is about 0.63 , and its value is $2105 \mathrm{Nm}$.

The analytical calculation value of the electromagnetic torque of DSRPMM is close to the optimal external split ratio under the finite element simulation value, but there is a certain difference in the electromagnetic torque value. This is mainly because the finite element simulation model takes into account the saturation factor of the motor and the actual size of the slot. The model of DSRPMM is simplified to a certain extent based on analytical calculation. The variation law of the DSRPMM electromagnetic torque is similar to that of the finite element simulation, which verifies the accuracy of the theoretical analysis above.

\section{Experimental Test of DSRPMM}

The prototype was made on the basis of theoretical analysis and finite element simulation of DSRPMM. The main size parameters of DSRPMM are determined, as shown in Table 2 . In order to verify the validity of the above analysis methods, an experiment is carried out on the DSRPMM. The cooling mode of DSRPMM is water cooling, and the insulation grade of the motor is $H$. The protection level of DSRPMM is IP67 for the dust-dense motor, which completely prevents the dust from entering. There will be no water immersion within $30 \mathrm{~min}$ when the motor is submerged by $1 \mathrm{~m}$ water. The cooling medium specification of DSRPMM is constant temperature $20^{\circ} \mathrm{C}$, the flow rate of the cooling medium is $20 \mathrm{~L} / \mathrm{min}$, and the water pressure of the cooling medium is stable at 45 Psi. The experimental test of the prototype is shown in Figure 16.

During the experimental test of DSRPMM, a total of 10 rotational speed points were selected within the working speed range of the prototype. The minimum speed point of
TABLE 2: Main dimension parameters of prototype DSRPMM.

\begin{tabular}{lcc}
\hline Parameters & Internal stator value & External stator value \\
\hline $\begin{array}{l}\text { Slot number } \\
\text { Poles }\end{array}$ & 72 & 72 \\
$\begin{array}{l}\text { Internal diameter } \\
(\mathrm{mm})\end{array}$ & 12 & 12 \\
$\begin{array}{l}\text { External diameter } \\
(\mathrm{mm})\end{array}$ & 158 & 225 \\
Yoke high (mm) & 13 & 368 \\
$\begin{array}{l}\text { Air gap (mm) } \\
\text { End wingding }\end{array}$ & 1.2 & 15 \\
length (mm) & 30 & 1.5 \\
\hline
\end{tabular}

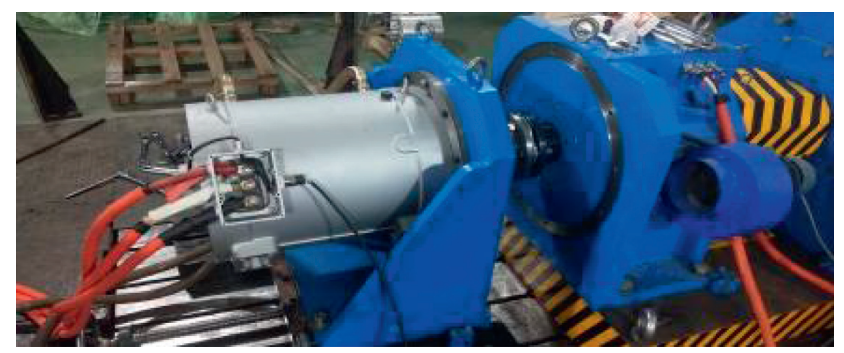

Figure 16: Experimental test site of DSRPMM.

DSRPMM is not greater than $10 \%$ of the maximum speed point of the motor. The interval between adjacent speed points of DSRPMM is not greater than $10 \%$ of the maximum speed. On the basis of the above points, the rated working speed point, the highest working speed point, and the lowest speed point corresponding to the continuous power of the motor should be tested. In order to ensure the overall accuracy of the test data, 5-10 torque points should be selected at each rotational speed point for testing. At the same time, the selection of torque test points should also include the following test points: the point at the continuous torque, the point at the peak torque, and the point at the peak power. The prototype was tested according to the above requirements, and the electric external characteristic curve of DSRPMM is shown in Figure 17.

It can be seen from the figure that the maximum output power of DSRPMM is $160 \mathrm{~kW}$ and the maximum electromagnetic torque is 1980 N.m. DSRPMM has high efficiency in the rated power operation within the full speed range. In addition to the peak speed point, the efficiency of the motor is above $90 \%$. The peak power of the motor attenuates when the speed of DSRPMM is greater than $1750 \mathrm{rpm}$, which is mainly due to the limited supply voltage of the battery, and the voltage of the motor is saturated.

By comparing and analyzing the rated power and the peak power in the full speed range, the efficiency of DSRPMM in the full speed range of the peak power is lower than that in the full speed range of the rated power. The experimental results of the prototype are consistent with the analytical calculation results and the finite element simulation results of the internal and external split ratios mentioned above. The accuracy of the analysis and design method of the internal and external split ratio of DSRPMM based on the copper consumption density and current 

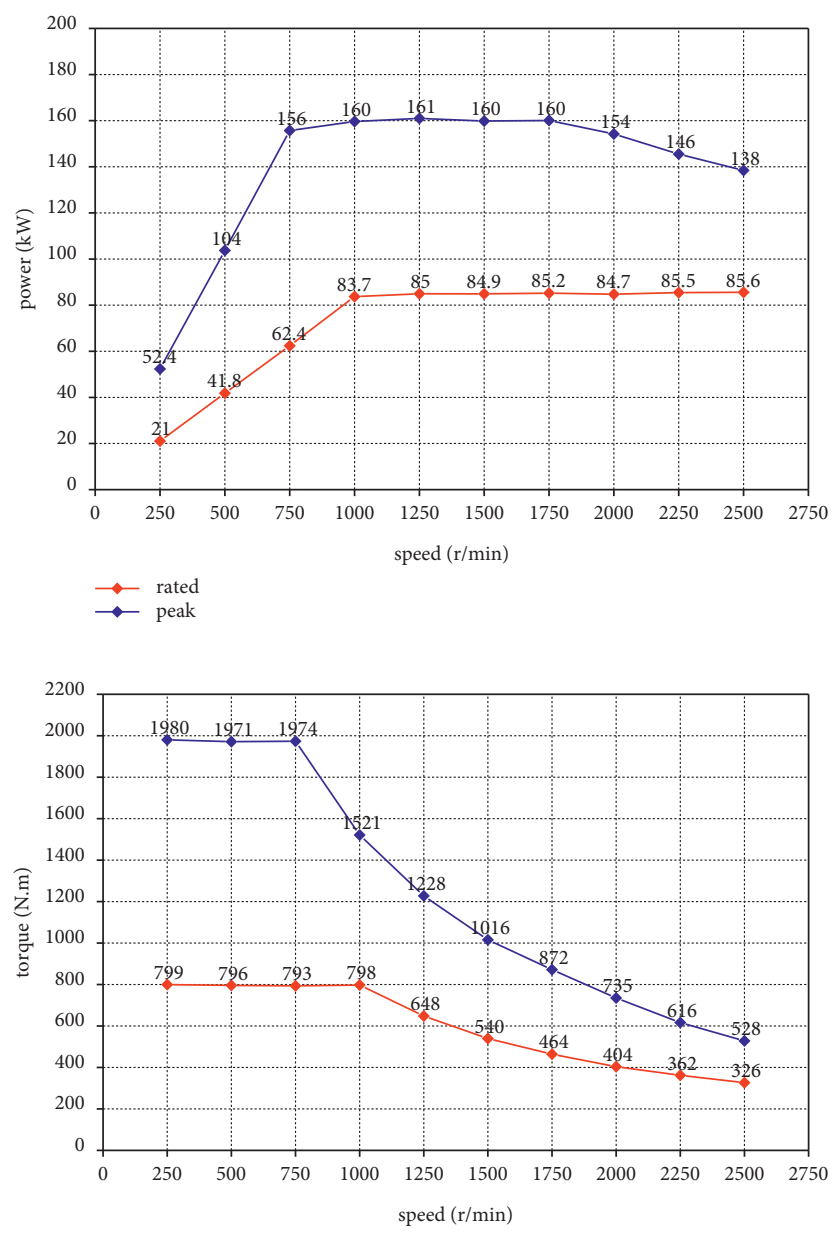

$$
\because \text { rated }
$$

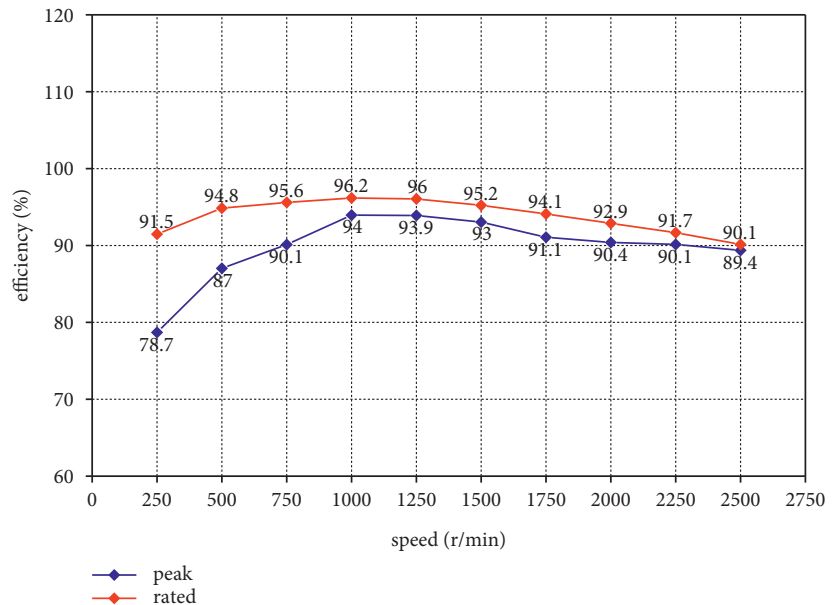

Figure 17: External characteristic curve of DSRPMM.

density was proved. In order to further analyze the efficiency distribution of the motor, the MAP of DSRPMM under electric and feed states is shown in Figure 18.

It can be seen from the figures, the maximum working efficiency of the motor exceeds 96\% when DSRPMM operates in electric state. The work area with motor efficiency greater than $85 \%$ accounts for about $85 \%$, and the work area with motor efficiency greater than $90 \%$ accounts for about $60 \%$. The maximum working efficiency of the motor exceeds $96 \%$ when DSRPMM operates in feed state, which is same as electric state. The work area with motor efficiency greater than $85 \%$ accounts for about $82 \%$, which is less than electric 

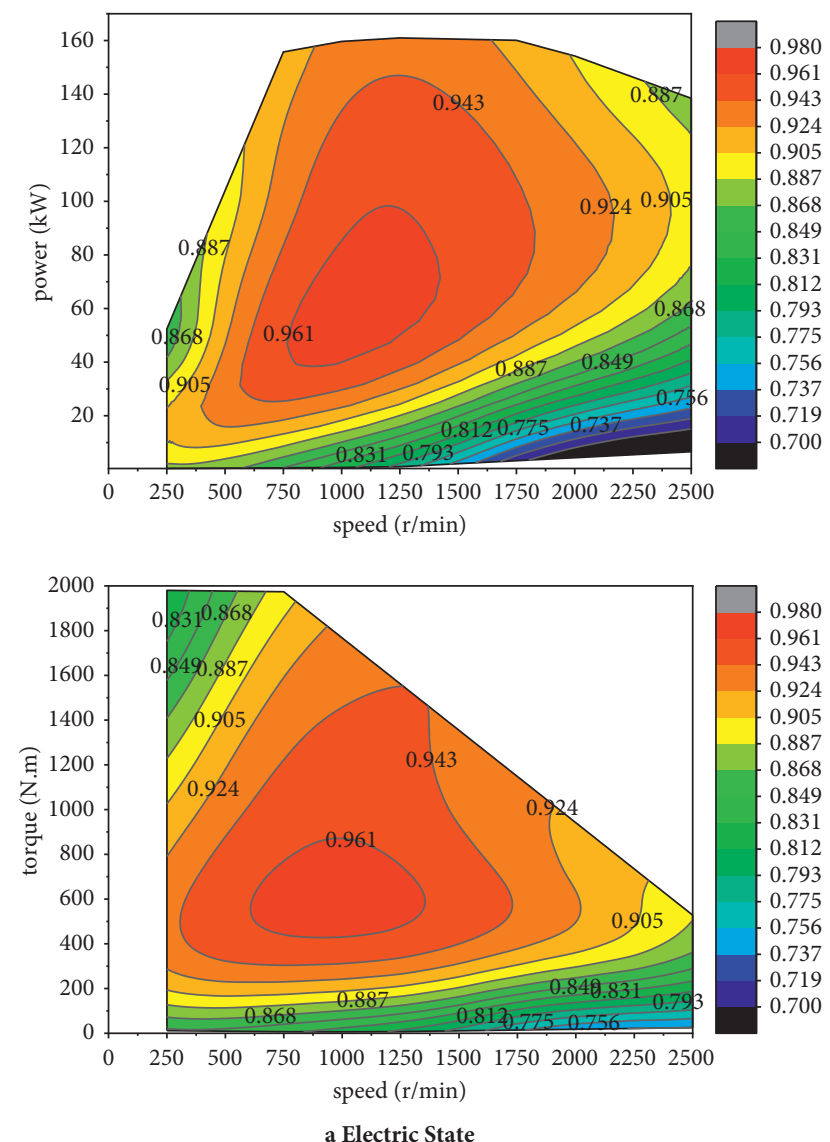
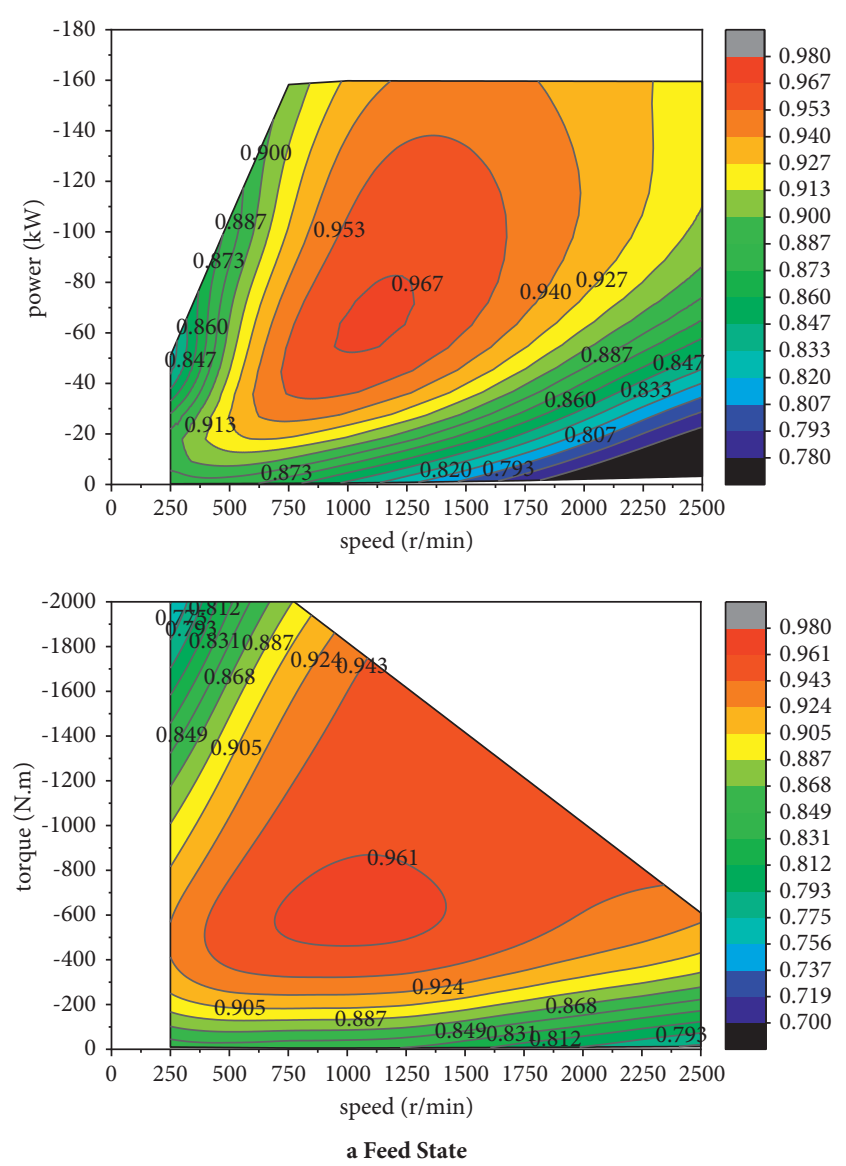

Figure 18: Efficiency MAP of DSRPMM under electric and feed states.

state. The work area with motor efficiency greater than $90 \%$ accounts for about 55\%, which is less than electric state. According to the working conditions of DSRPMM, the motor works in the electric state for a long time, and the duration is small in the feed state. The efficiency difference of DSRPMM in the electric and feed states conforms to the application condition of the motor.

\section{Conclusion}

In this paper, an optimal design method of DSRPMM split ratio based on copper consumption density and current density is proposed. The method restricts the overall heating of the motor and the local short-time heating of the winding by limiting the copper consumption density and current density. The relationship between electromagnetic torque and split ratio is studied and analyzed. The expression of the optimal split ratio based on the maximum electromagnetic torque of copper consumption density and current density DSRPMM is deduced. The analytical value of the optimal split ratio is verified by using the finite element platform. The experimental test is carried out on the prototype, and the conclusions are as follows:

The optimal internal and external split ratio of DSRPMM is related to the magnetic flux density coefficient and the number of motor poles. When the magnetic flux density coefficient remains constant, the optimal internal split ratio decreases with the increase of the number of motor poles, and the optimal external split ratio increases with the increase of the number of motor poles.

The electromagnetic torque of DSRPMM increases with the increase of internal split ratio. The electromagnetic torque of DSRPMM increases first and then decreases with the increase of the external split ratio. The larger the flux density coefficient, the smaller the optimal external split ratio and the larger the maximum electromagnetic torque of the motor. The optimal internal and external split ratio of the motor varies under different magnetic loads. In the process of DSRPMM design, the internal and external split ratio should be selected according to the change of magnetic load.

The optional region of the internal and external split ratio becomes smaller when the copper consumption density and current density are restricted at the same time.With the increase of the flux density coefficient, the optional region of the internal split ratio torque increases, and the optional region of the external split ratio torque increases first and then decreases.

When the flux density coefficient is less than 0.6 , there is an intersection point between the output electromagnetic torque curve under the restriction of copper consumption density and the restriction of current density. When the flux density coefficient is greater than or equal to 0.6 , the two output electromagnetic torque curves have no intersection point. At this time, the output electromagnetic torque curve 
with limited copper consumption density surrounds the output electromagnetic torque curve with limited current density. The output torque of DSRPMM is mainly determined by the current density.

\section{Data Availability}

The data used to support the findings of this study are available from the corresponding author upon reasonable request.

\section{Conflicts of Interest}

The authors declare that they have no conflicts of interest.

\section{References}

[1] K. Liu, B. Y. Zhang, G. H. Feng, and J.-R. Liu, Research on Drilling Technique of Permanent Magnet Motor Direct-Drive Winch Based on Fuzzy Logic, IOS Press, Amsterdam, Netherlands, 2015.

[2] K. Liu, B. Y. Zhang, and G. H. Feng, "Research on electromagnetic vibration and noise characteristics of dual sided rotor permanent magnet synchronous motor," Transactions of China Electrotechnical Society, vol. 35, no. S2, pp. 387-394, 2020.

[3] Y. B. Wang, M. Cheng, Y. Fan, and K. T. Chau, "Design and electromagnetic performance analysis of double stator permanent magnet brushless machine for power splitting," Transactions of China Electrotechnical Society, vol. 25, no. 10, pp. 37-43, 2010.

[4] Y. B. Wang, M. Cheng, W. Hua et al., "Analysis and optimization of split ratio for double-stator permanent magnet brushless machine," Proceedings of the CSEE, vol. 30, no. 30, pp. 62-67, 2010.

[5] J. Xia, "Reserch and design of double-stator permanent magnet synchronous in-wheel motor," Master's Thesis, Harbin Institute of Technology, Harbin, China, 2008.

[6] X. P. Liu and H. Y. Lin, "Method for reducing cogging torque in dual-stator permanentmagnet synchronousmachine," Journal of Southeast University, vol. 37, no. 4, pp. 618-622, 2007.

[7] X. P. Liu, Z. A. Yu, and J. W. Liang, "Study on cogging torque in dual staor permanent magnet generators based on FEM," Micromotors, vol. 40, no. 12, pp. 31-34, 2007.

[8] X. P. Liu, H. Y. Lin, and C. F. Yang, "A method of determining the relative winding axises position of dual-stator permanent magnet electrical machine," Transactions of China Electrotechnical Society, vol. 24, no. 4, pp. 60-65, 2009.

[9] Y. B. Wang and M. Cheng, "Inductance characteristic analysis of double stator permanent magnet brushless machine," Micromotors, vol. 44, no. 7, pp. 20-22, 2011.

[10] D. Zhang, "Design and analysis of a novel double-stator permanent magnet machine" Ph.D. Dissertation, Shanghai University, Shanghai, China, 2007.

[11] X. P. Liu and X. X. Huang, "Design of a novel double-stator permanent magnet synchronous wind generator with low speed," Micromotors, vol. 39, no. 8, pp. 25-27, 2006.

[12] X. P. Liu and X. X. Huang, "3-D FEA and experiment study of novel dual-stator hybrid excited wind generator," Proceedings of the CSEE, vol. 28, no. 20, pp. 142-146, 2008.

[13] W. X. Huang, X. F. Wang, Z. C. Wei et al., "Starting performance simulation of the twin stator induction motor using
MATLAB," Small \& Special Electrical Machines, no. 2, pp. 7-9, 2002.

[14] A. Rahideh and T. Korakianitis, "Analytical open-circuit magnetic field distribution of slotless brushless permanentmagnet machines with rotor eccentricity," IEEE Transactions on Magnetics, vol. 47, no. 125, pp. 4791-4808, 2011.

[15] J. Perahia and C. V. Nayar, "Generalized machine theory applied to a three phase twin stator squirrel-cage induction motor," International Journal of Electrical Engineering Education, vol. 31, no. 2, pp. 167-183, 1994.

[16] H. Y. Wang, X. P. Yan, S. Huang, and T. Sui, "Design and torque analysis of dual-stator permanent magnet motor for electric motorcycle," Micromotors, vol. 44, no. 1, pp. 7-10, 2011.

[17] B. Q. Kou, Q. F. Zhang, S. K. Cheng et al., "Analysis of commutation in three-phase rectifier of doubly salient electromagnetic generator," Proceedings of the CSEE, vol. 28, no. 20, pp. 111-117, 2008.

[18] B. J. Ge, S. Y. Xiao, Z. H. Liu et al., "Analysis and restrain strategy of cogging torque for double-stator hybrid direct drive motor with series magnetic circuit," Proceedings of the CSEE, vol. 25, no. 4, pp. 143-150, 2005. 